\title{
Le locus génétique de la maladie d'Alzheimer diffère de celui de la protéine amyloïde
}

Dans son numéro de mai 1987 ( $n^{\circ} 5$, vol. 3, p. 254 et 256) médecine/sciences se faisait l'écho des découvertes récentes sur le gène de la maladie d'Alzheimer. Le fait essentiel était la localisation sur la même région du chromosome 21 du gène responsable de la maladie dans les formes familiales (à transmission autosomique dominante) et de celui de la protéine amyloïde qui s'accumule dans le cortex cérébral des sujets atteints. Il en découlait l'hypothèse que les deux gènes n'en faisaient qu'un, et que la maladie était liée à une anomalie ou à une surproduction, de la protéine. Dans cette optique, la fréquence de troubles précoces, cliniques et anatomiques, du type Alzheimer dans la trisomie 21 avait conduit à invoquer une duplication du gène de la protéine amyloïde dans la maladie d'Alzheimer, que semblaient corroborer des observations préliminaires. Cependant des objections se faisaient jour : outre les difficultés techniques, on peut rappeler que des lésions anatomiques semblables ont été signalées par exemple dans les troubles neurologiques de l'île de Guam $\left(\mathrm{m} / \mathrm{s} n^{\circ}\right.$ 7, vol. 3, p. 426), dus à une intoxication exogène d'origine non génétique. Deux articles récents $[1,2]$, qui ont réclamé des collaborations internationales étendues, font rejeter l'hypothèse de l'identité entre les deux loci. Neuf familles en tout ont été étudiées, chacune incluant de nombreux sujets atteints de maladie d'Alzheimer. Utilisant des clones d'ADN complémentaire du gène de la protéine amyloïde, on a obtenu des polymorphismes de restriction permettant de suivre la transmission de la protéine amyloïde dans la descendance, et d'en évaluer la liaison éventuelle avec le gène de
La fréquence des recombinants s'est montrée telle que toute identité entre les deux loci peut être exclue. Le gène de la protéine est vraisemblablement lié à celui de la superoxyde dismutase en $21 \mathrm{q}$ $21-22$, très proche de la région dont la duplication est indispensable à l'apparition clinique du mongolisme. Qu'il en fasse ou non partie, dans les familles étudiées par les deux groupes, aucune duplication du gène de la protéine amyloïde n'a pu être retrouvée chez les malades. Quant au gène de la maladie d'Alzheimer familiale, il est certainement plus proche du centromère, à une distance d'au moins $10 \mathrm{cM}^{*}$ de celui de la protéine amyloïde.

Il nous faut donc faire notre deuil de l'hypothèse uniciste, bien que la proximité des deux loci sur le même chromosome reste curieuse. Dans quel sens peut-on prévoir l'orientation des recherches futures ? Les études sur le gène de la maladie d'Alzheimer vont certes se poursuivre. Toutefois l'identification précise du gène risque de s'avérer difficile car le nombre des formes familiales est beaucoup plus faible que pour la mucoviscidose ou la maladie de Duchenne. En revanche, un coup de fouet va être donné aux travaux sur la (ou les) protéine(s) amyloïde(s). La plupart des travaux concernent la "protéine A4 ", de 4000 daltons, dont le précurseur semble être un polypeptide de 92000 daltons, présent dans les membranes des cellules cérébrales, et dont le messager serait particulièrement abondant. Chez les malades pourrait se produire une dégradation anormale de cette protéine membranaire, aboutissant à l'accumulation de protéine A4. Cette hypothèse peut

* M : centi-morgan, unité de recombinaison. avoir des prolongements thérapeutiques, car elle conduit à rechercher des agents actifs susceptibles d'interférer avec une protéolyse excessive.

Signalons enfin [3] que la présence d'ubiquitine dans les pelotons est bien démontrée. On sait qu'elle intervient $\left(\mathrm{m} / \mathrm{s} n^{\circ} 5\right.$, vol. 2, p. 283) dans la dégradation des protéines ; sa présence témoigne de l'existence dans les neurones atteints, de protéines reconnues par eux comme anormales et dont ils tentent de se débarrasser par la voie de l'ubiquitine.

Dernière heure : trois articles sont parus dans le numéro de Sciences du 30 octobre 1987. Tous trois confirment l'absence de duplication du gène de la protéine $\beta$ amyloïde.

J.-C. D.

1. Van Broeckhoven C., Genthe A.M., Van denberghe A, et al. Failure of familial Alzheimer's disease to segregate with the A4-amyloid gene in several European families. Nature $1987 ; 329: 153-5$

2. Tanzi RE, St-Georges-Hyslop PH, Haines JL., et al. The genetic defect in familial Alzheimer's disease is not tightly linked to the amyloid $\beta$-protein gene. Nature $1987 ; 329$ : 156-7.

3. Anderton $\mathrm{BH}$. Tangled genes and proteins. Nature $1987 ; 329$ : 106-7.

4. St-Georges-Hyslop, Tanzi RE, Polanski RJ, et al. Absence of duplication of chromosome 21 genes in familial and sporadic Alzheimer's disease. Sciences 1987; 238 : 664-6.

5. Tanzi RE, Bird ED, Latt SA, Neve RL The amyloid $\beta$-protein gene is not duplicated in brain from patients with Alzheimer's disease. Science $1987 ; 238: 666-9$.

6. Podlisny MB, Lee G, Selkoe DJ. Gene dosage of the amyloid precursor protein in $\mathrm{Alz}$ heimer's disease. Science $1987 ; 238$ : 669-71. 